\title{
Construction of College Students Business Platform under the Age of Internet +
}

\author{
Li Zhang ${ }^{1, a}$ \\ ${ }^{1}$ Xi'an International University, Xi'an, Shaanxi, 710077 \\ a email
}

Keywords: College Students, Business Platform, Internet+

\begin{abstract}
With the advent of social economy, the development of technology and the age of the Internet + , it provides an unprecedented opportunity for business students. National Human Resources and Social Security also provides business students many preferential policies, in the "Internet +" background, entrepreneurial market has an unprecedented potential. Internet + age, college students, professional and play to our strengths and actively explore the College division, the actual needs of students, "College Student should tap the potential market prospects Universities, research and development of commercial integrated digital campus platform, explore the road of entrepreneurship.
\end{abstract}

\section{Introduction}

The 21st century is rapidly changing information age, young and dynamic students on accepting new information, new knowledge, new ideas ability to show a clear advantage, becoming one of the groups most innovative entrepreneurial potential; therefore, higher education in culture innovation and entrepreneurship, chain plays an important role. In North America and other developed countries, namely, innovation and entrepreneurship education be taught as a discipline in the institutions of higher learning in the 20th century, 40 years, innovation and entrepreneurship education in Chinese universities in recent years it has also been raised to an unprecedented new heights. However, since the existing system of university curriculum innovation and entrepreneurship is not perfect, the course content is still stuck in innovation and entrepreneurship, basic concepts, theories and knowledge, lack of practice and training platform, resulting in students theoretical knowledge and practical ability of touch, unable to penetrate its inner relationship. Meanwhile, the competition in the market risk in being environment, curriculum teaching time constraints, teachers can not provide practice conditions for students to innovation and entrepreneurship in practice, case teaching can not be achieved dynamic market competition and corporate innovation and entrepreneurial activity, students in the classroom are still unable to cultivate innovation and entrepreneurship combat skills, the learning process is still passive acceptance of knowledge, the lack of self-learning and exploration capabilities. Therefore, innovation and entrepreneurship education in the university system constituting the curriculum, teaching models and audience size, have been unable to meet the pressing social needs of the modern enterprise innovation and entrepreneurial decision-making talents. Therefore, how to adapt to the development of the situation, the use of modern information technology, deepen the training model, speed up the training of high-quality modern enterprise innovation and entrepreneurial decision talent is an urgent need to address the major issue of higher learning innovation and entrepreneurial decisions facing our country Talents .

Internet + employment and entrepreneurship is a modern profession, Skills, New model development environment, which is the entry point for Internet + employment business application platform, the focus is more efficient, breakthrough talent cultivation of college students employment and entrepreneurship large data foothold for college students, for the country, for the government to provide accurate information services. According to statistics, in 2014 the total number of university graduates in the country up to eight million, while the employer hiring plans of enterprises and institutions was diminishing year by year, so reverse there are two factors: First, 
employees of state-owned enterprises saturated amount, the second is the country each year there are about 120,000 private enterprises are facing bankruptcies "in a large group of university graduates flock to the collective society, when there have been the most difficult in the history of employment season "Therefore, the state had to introduce relevant policies, have to promote and encourage strong and brave entrepreneurial college graduates, while entrepreneurship to create jobs" local governments are actively supporting policies introduced business students, college students start their own businesses to increase support, while colleges and universities is also a positive response, do ideological work of college students change career outlook and deepen the cultivation of students' professional skills, training students professional skills and professionalism. "but these measures are progressive, Unable to solve practical problems in a short time, because the employment of university graduates are college students venture into the community undisputed rigid demand, therefore, the author constructed a set of employment and entrepreneurship internet application platform for building programs based on years of market research for the country to solve practical problems.

\section{Feature of Internet + Business Platform}

Has a strong customer base in the Chinese Internet, according to statistics, there are over 700 million people in the application of Internet technology, most of them are the backbone of the country, there is expertise, Have the technical ability, Have a good potential for development of youth organizations, therefore, application platform to have powerful functions and features. Students 'employment and business platform consists of two parts, applications and support system components, applications can achieve students' employment business-related information dissemination, as well as employment and entrepreneurship in career planning and career testing, support systems from big data analysis system, Employment Innovative Information Audit system, resource integration system, vocational training system, business service system composed of a large complete data analysis and exchange of technology research and development and other major functions. Specific functions and features are as follows:

Network security is a cost a cost, a powerful business platform of employment and we must first ensure network security technology, Personal information. Aiming at the provincial and municipal government support policies for entrepreneurial college graduates, to propose increasing the establishment of college students venture safeguard mechanism to address individual students start the process of a large number of investment and financing tables encountered many problems.

Employment and entrepreneurship on the Internet + application platform business model, business model, Professional mode, Management, Government information model organic convergence, so that employment business information publishing authenticity, Technical support precise, Review and evaluation of the authority, Securing venture cooperation, policy-based information in a timely manner.

Big data support System. Success-oriented employment of university students entrepreneurial information technology as a support to have a big data platform, the demand for professional employment in recent years, college students, Business, Technological regional differences, Operating scale enterprises, Broad market prospects, and even employment and start-up costs, etc. implementation collected data, predictive analysis can provide employment and entrepreneurship for college students making programs to address present on the employment of university students career path from the source, low pay, recessive entrepreneurial, fraud and other issues. Big Data analysis can provide a variety of real employment business information to the graduates, ARTS employment and entrepreneurship trend analysis in different areas of expertise and employment success rate of entrepreneurship analysis, employment and entrepreneurship indicate the direction of college students, but also provides data analysis and professional needs technical data analysis, employment and entrepreneurship also provide accurate data for employers and government departments. Build a solid foundation for the establishment of large-scale employment of university student business platform.

. Era of the Internet allows remote control, 3G, Fast data analysis and processing advantages, 
Cloud computing and other advanced technologies into full play and the employment of college students start the application, different for different colleges graduates of private groups to provide employment and entrepreneurship expertise location-based services, according to their professional advantage, technical specialty area choice of employment and entrepreneurial orientation, automatic optimization of data platform provides the optimal solution.

\section{Construction and Maintenance of Business Platform}

Targeted research and analysis of APP give accurate product positioning, entrepreneurial team to highlight APP UI design simple novel, functionally Students strive to meet consumer characteristics Main functions should cover campus information platform: users can log in name and by password using the mobile client to facilitate the work of teachers and students to learn information about the query, based on the personal experience of local university students, and sorting through information sources, the operations team targeted design and development, more in line with our students the habit, compared similar products more to earth; query build communication platform to facilitate the exchange offer community friends buy information consulting business also some hobbyists, you can directly apply to participate in the community to participate in buy add friends on the phone, enriching the college life after school; Colleges offer a variety of nearby shopping and entertainment catering accommodation and secondary trading, etc., to provide advertising platform for businesses, information campaigns and discount efforts and provide contact information, this feature is also a source of income commercial complex.

Push sports daily learning experience as a part-time experience surrounding Travel Tips Food Guide, etc. Users can subscribe to one or more columns, the push is another part of the R \& D team APP income using micro-text photos video form, sharing and classmates part-time motion study with food beauty describe the mood to meet college students eager to share impressions and psychological needs, but also to show users more intuitive consumption effect.

College-based mobile client business platform features both APP localization personalized, user groups clearly defined as university teachers and students, a solid basic user products is based on fundamental business platform APP. APP entrepreneurial business profit model, it can be divided into trial during, and formally launched two parts:

To enhance teachers and students to download the user's usage rate and increase the impact of their own businesses APP College student internet users in. APP own businesses are developed by our students entrepreneurial team, the advantage is more prominent, both to understand the needs of student users, but the disadvantage more obvious in the level of technology to be perfected, the present application are set feedback column in each module, user and development team feedback. trial process, but also to optimize the collection problem, revenue in this period of gradual improvement Origin, then online survey: the data needs of companies providing business surveys can increase revenue and get the data using these proceeds to solve this problem of university independent entrepreneurs APP, APP is conducive to the gradual improvement of each module.

Own businesses APP explicit user location and campus popularity to attract business ads, can be introduced PubMed test series professional qualifications and other learning materials; appliances, sports equipment dance inside and outside the secondary market to buy part was released more classified advertising messages.

Universities to be self-employed APP after gradual improvement can be dual-mode ordinary users and members of the user's membership can be better service, more preferential policies, the use of accumulated points to redeem gifts in the form of at least a certain amount of consumption and reduce the amount of activity, Switch to encourage ordinary users and members of certain formalities annual fee.

APP Upgrade Update function bug fixes adaptation system upgrade due to a software design to the various branches of learning life sales, entrepreneurial team need to constantly improve and update, while using APP Can features, real-time online updates APP application management, application push functionality, upgrades the new version of the process, the user is prompted to choose whether to update a good user experience, increase user stickiness of the application. 
Due to the escalating APP and mobile phone systems, APP background management functions should also be upgraded simultaneously, increase the backup recording and statistical analysis of data, use analytics big data and facilitate a more accurate tracking of consumer groups, to find the user's purchase hot and there are pushed to target customers for the needed goods.

\section{Conclusion}

Students active community is a worthy the focus of the society and there is a great significance in the construction of harmonious society in China's development system. In the context of the Internet + age, students should actively participate in the entrepreneurial action to allow themselves to be a new era of talents.

\section{Acknowledgements}

2016 Xi'an social science planning project " Construction of Xi'an College Students Business Platform under the Age of Internet +" project number: 16Y134

\section{References}

[1] Protopsaltis, A., et al. Start up EU: Using Game-Based Learning and Web 2.0 Technologies to Teach Entrepreneurship to Secondary Education Students[C]. 7th European Conference on Games Based Learning. 2013. 1:484.

[2] Bragg, S. and N. Henry, Order 121 - Study on Support to Indicators on Entrepreneurship Education[C]. Final Report. 2011, GHK: Birmingham.

[3] Hainey, T., T.M. Connolly, M.H. Stansfield and E.A. Boyle, The Differences in Motivations of Online Game Players and Offline Game Players: A Combined Analysis of Three Studies at Higher Education Level [J]. Computers and Education. 2011, 57(4): p. 2197-2211.

[4] Amri Y. A Conceptual Framework for Serious Games [J].The 9th IEEE International Conference on Advanced Learning Technologies, 2009.

[5] Scott W. O’ Leary-Kelly, Benito E. Flores, The integration of manufacturing and marketing/sales decisions: impact on organizational performance [J]. Journal of Operations Management, 2002 (20): 221-240. 